\title{
Planktonium: Photo series and short film (15 min) about the unseen world of microscopic plankton
}

\author{
Planktonium : Courts métrages et séries de photos sur le monde caché \\ du plancton microscopique vivant
}

\section{Jan van IJken}

RÉSUMÉ. Planktonium is a short film about the unseen world of living microscopic plankton. It is a voyage into a secret universe, inhabited by alien-like creatures. These stunningly beautiful, very diverse and numerous organisms are unknown to most of us because they are invisible to the naked eye. However, they are wandering beneath the surface of all waters around us and they are of vital importance for all life on earth.

Jan van IJken filmed the plankton through his microscopes, revealing the beauty and delicate structures of the minute organisms in the finest detail. The film is without any voice-over or explanation.

Renowned Norwegian artist Jana Winderen made a sound composition for the film. She is recording audio environments and creatures which are hard for humans to access, both physically and aurally - deep under water, inside ice or in frequency ranges inaudible to the human ear.

Phytoplankton (small plant-like cells) are producing half of all oxygen on earth by photosynthesis, like plants and trees do on land. Zooplankton are forming the base of the food chain of aquatic life. Plankton are also playing an important part in the global carbon cycle. The plankton are threatened by climate change, global warming and acidification of the oceans.

KEYWORDS. Plankton, arts, science, microphotography, microscopy, nature, short film, microworld.

Since a few years, I have been fascinated by plankton. The delicate structures, shapes and colours of these tiny organisms are stunning. And because they are often transparent, you can see their inner workings. The plankton are extremely numerous; in certain blooms, they are even visible from space! However, only few people are aware of all this beauty around the corner, because the tiny organisms are invisible to the naked eye. Only through a microscope they can be observed. Yet these organisms are completely unknown to most people, while they can be found in large numbers in every water around the corner. It's an unknown universe, full of alien-like creatures.

For me, the exquisite beauty and the importance of these tiny wonders were enough reason to start a photo and film project about this unseen microcosm. It took me more than 3 years to finish the project. My basic idea for the film and photo series was to present the plankton as living organisms in all their splendid beauty, colours and fine details. I take the viewer on a journey to a hidden universe, full of strange and alien-like creatures. There is no commentary or voice-over in the film, so the viewers can immerse themselves in this unknown, magical world. It's a typical project on the interface of art and science.

The plankton is the source of life; they produce approximately half of all oxygen and the zooplankton forms the basis of the aquatic food web. Some organisms have been on Earth in unaltered form for millions of years and have invented the oxygen or have been the basis of important evolutionary developments. So, without them, we wouldn't even be there! Organisms like cyanobacteria are still in our waters today in unchanged form, which I find very fascinating.

Phytoplankton (plant-like bacteria and microalgae) produce an estimated half of all oxygen on Earth. They use the process of photosynthesis, just like plants and trees on land do. Zooplankton are eating the phytoplankton and are the primary consumers in the sea, e.g. single-celled ciliates. These 
small herbivores are eaten by larger predatory zooplankton like copepods and crab larvae. They form the basis of the aquatic food web, so without plankton there would be no fish!

Plankton also play a very important role in the global carbon cycle and on the Earth's climate. Without the myriad creatures, the oceans would be empty of life, and we would have no oil or gas reserves. So plankton plays a vital role in our lives, even though most people don't realize this. However, the plankton is threatened by global climate change, rising sea temperatures, changing ocean currents and acidification of the oceans. These changes bring consequences for the abundance, the distribution and seasonality of the plankton. It may have a big impact on the marine food web, the ecology of our planet and on ourselves.

I have taken samples from all kinds of waters in The Netherlands; from the sea, puddles, small ponds in dunes and forests, etc. Each water has its own biotope in which the organisms are perfectly adapted to their environment). My catches were often full of surprises. Back home, I investigated the catch under the stereomicroscope, prepared the samples on an object glass, and filmed or photographed the plankton with my Sony full frame system cameras through my light microscope. I wanted to present the plankton as living organisms. That is why the film is a combination of timelapse and video. Most photos of the photo series were produced with the technique of focus stacking; by combining many photos with a different focus point, one sharp image can be made.

On December 31, 2020 I stopped sampling, filming and photographing to start editing. This was not an easy job because of the large amount and diversity of visual material. The selection process was quite difficult. In the end, the film is 15 minutes of duration. I edited mainly on form, colour and rhythm with great help of Metje Postma. I didn't want any commentary or voice over in the film because I see my film more as an art film than as an educational or science film.

I didn't want music in the film, but the sound from nature, in this case underwater sounds. I did research on the internet and found Jana Winderen, a renowned Norwegian sound artist who has specialized in producing underwater sound recordings with her hydrophones for over 20 years. She was prepared to make a sound composition for my film. A wonderful collaboration; picture and sound match really well.

The world premiere of the film was at Ji.hlava Documentary Film Festival in the Czech Republic, followed by the Dutch premiere at Inscience Film Festival in Nijmegen. The film has since been purchased as a video artwork by Museum De Lakenhal in Leiden (my hometown) and will be screened there as a part of Leiden European City of Science from 22 January 2022. I have also published a collector's box of the project in a very limited edition of 35 copies. (More info on my website). The online release of the film was on November 17 with publications from National Geographic, Colossal and Aeon, among others.

The film can be streamed / downloaded here: vimeo.com/ondemand/planktonium

More information: www.janvanijken.com 


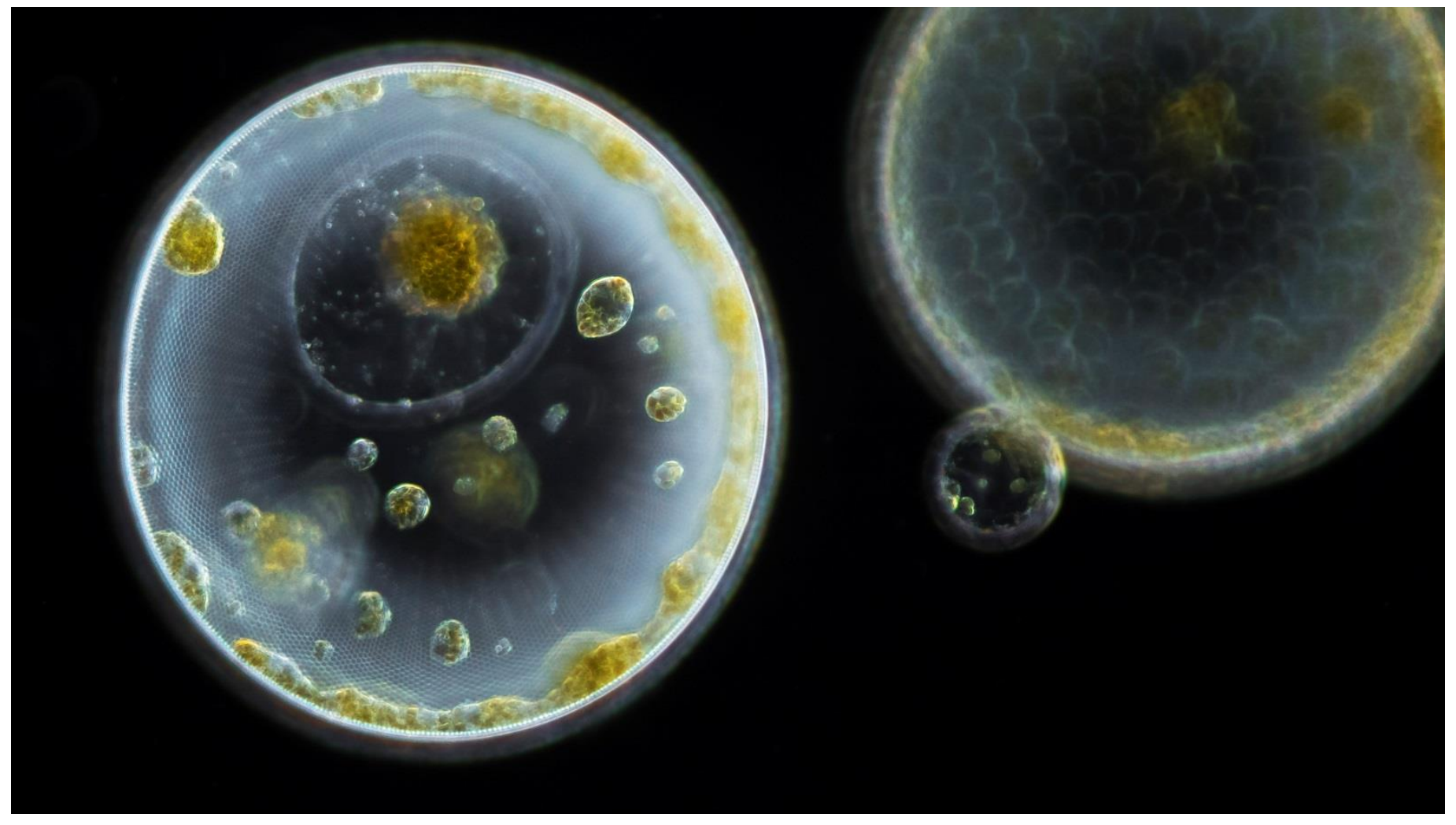

Coscinodiscus (diatoms)

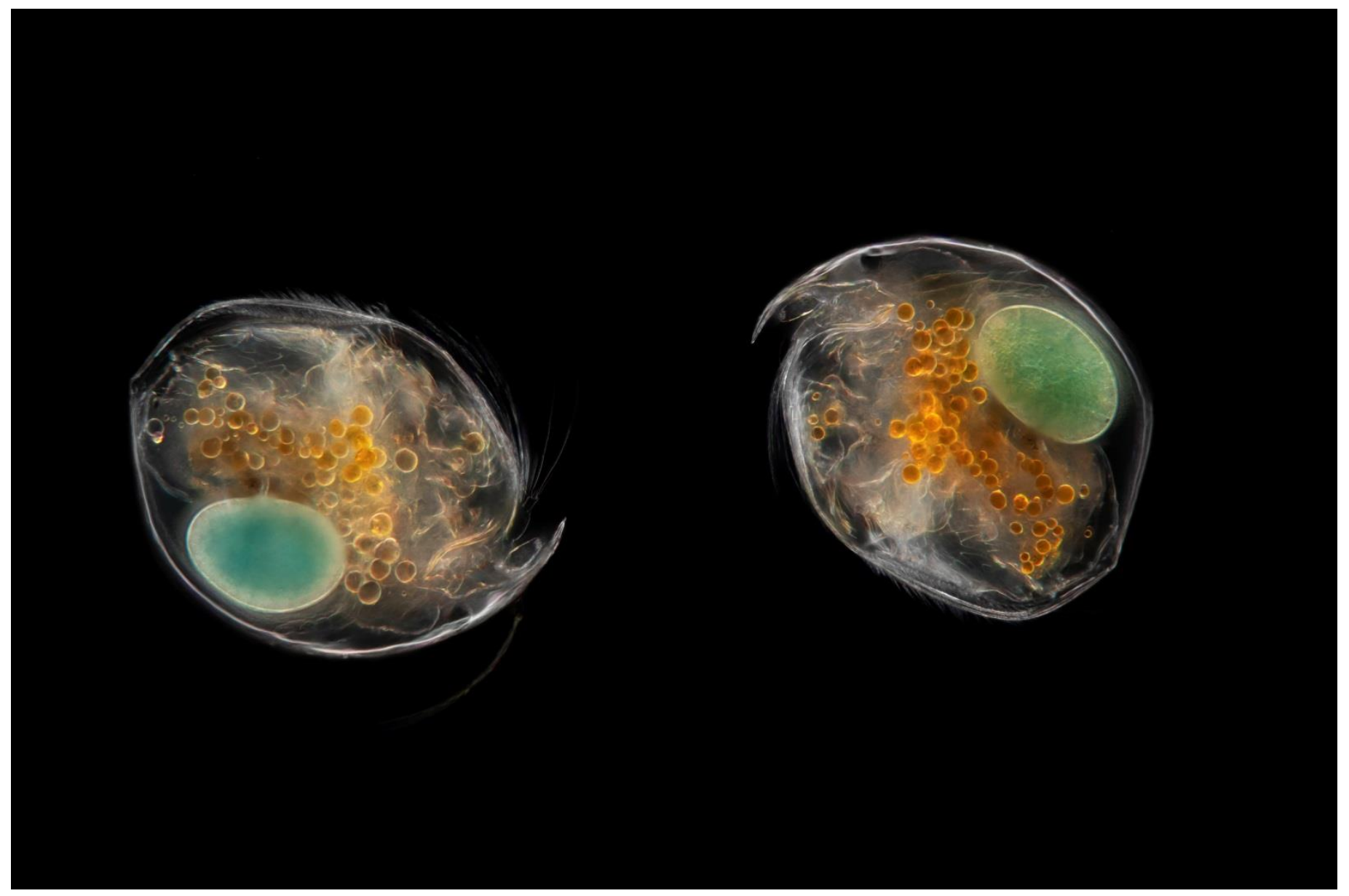

Chydorus sphaericus (water fleas carrying egg) 


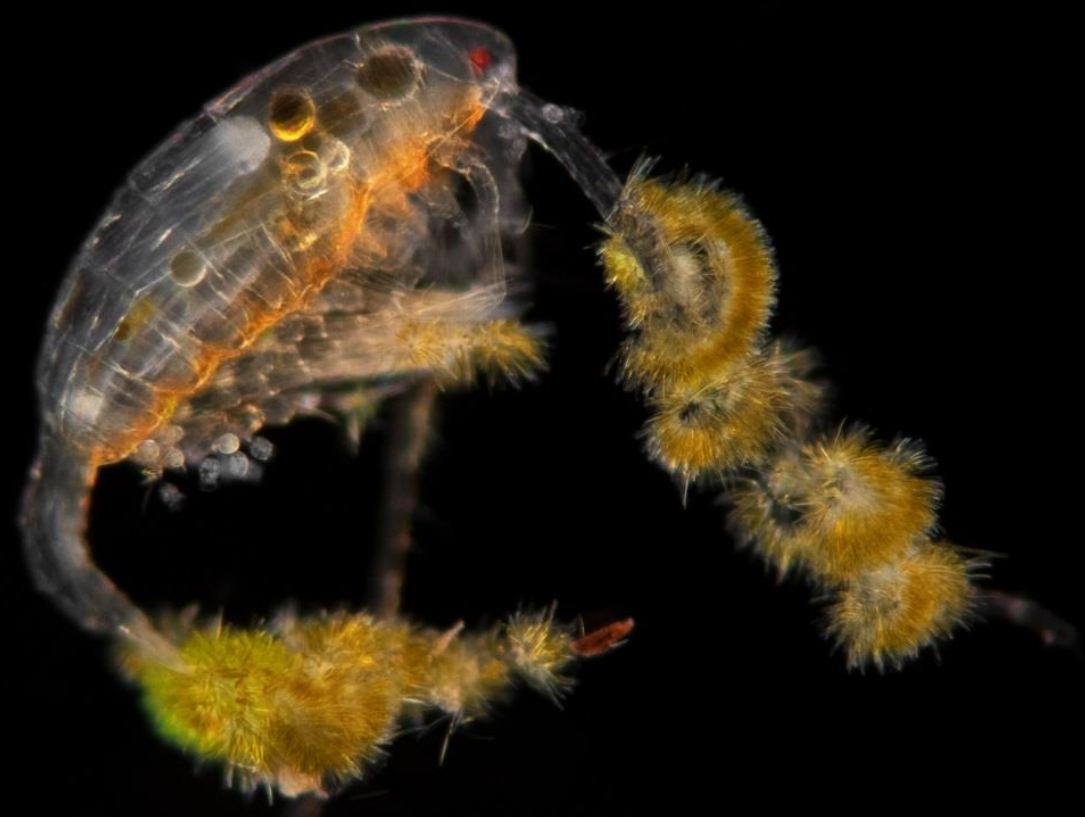

\section{Cyclops (copepod carrying diatoms)}

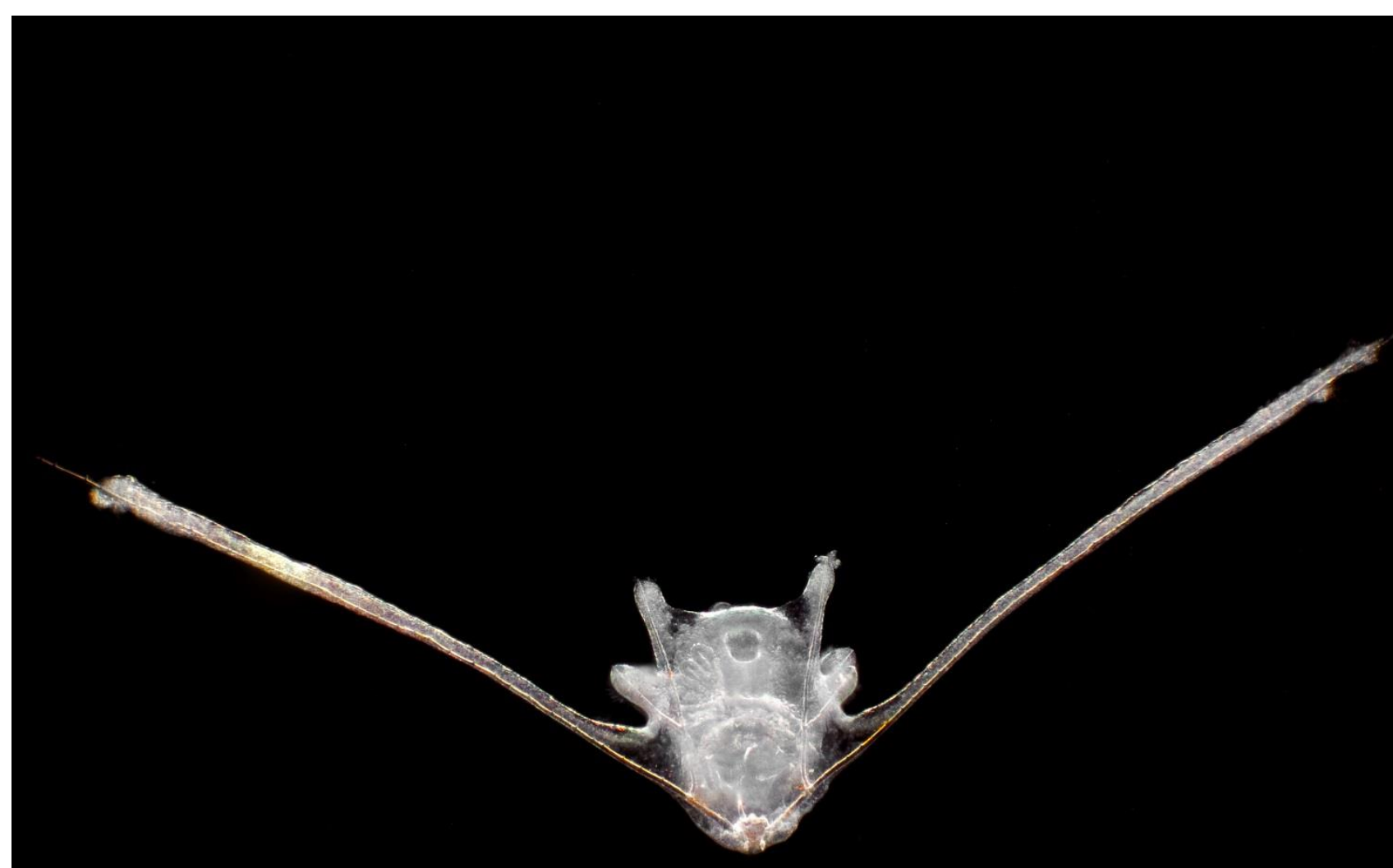




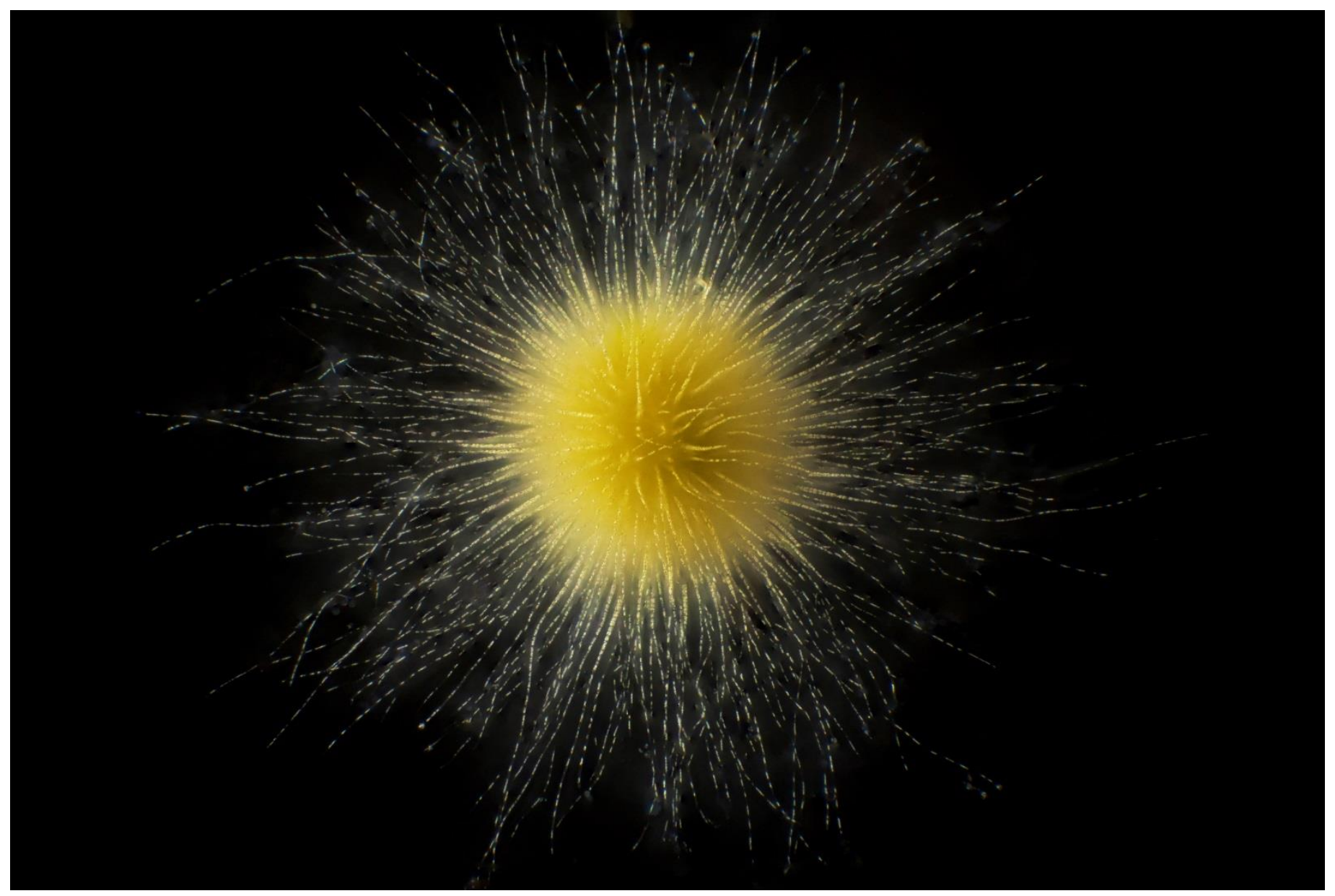

Gloeotrichia (cyanobacteria) 